\title{
Determination of Daily Sperm Production (DSP) in Rabbit (Oryctolagus cuniculus) Bucks using Testicular Parameters
}

\section{Olarotimi, Olumuyiwa Joseph ${ }^{1,2}$, Sokunbi Olujide Adedamola ${ }^{2}$, Abdullah Abdur-Rahman ${ }^{3}$}

\author{
${ }^{1}$ Livestock Feeds Plc, P.M.B. 7119, Aba; Abia State, Nigeria \\ ${ }^{2}$ Department of Animal Science, University of Ibadan, Ibadan, Nigeria. \\ jide.sokunbi @ gmail.com, +234816-115-7628 \\ ${ }^{3}$ Department of Animal Science, Babcock University, Ilishan-Remo, Nigeria. \\ arabdullah2002@yahoo.co.uk, +234803-536-3338
}

Article No.: 070715086

DOI: 10.15580/GJAS.2015.4.070715086

Submitted: 07/07/2015

Accepted: 17/07/2015

Published: $31 / 07 / 2015$

${ }^{*}$ Corresponding Author Olarotimi Olumuyiwa Joseph

E-mail: joemuyi@gmail.com

Phone: $+234803-565-0055$

Keywords:

External genitalia Morphometric

indices, Daily Sperm Production,

rabbit, Post slaughter traits
The study investigated the breeding soundness of male rabbits using daily sperm production (DSP). The relationships between different testicular parameters and the DSP were investigated. A total of twenty (20) pubertal bucks with mean body weights of $1.71 \pm 0.03 \mathrm{~kg}$ ranging from 1.66 to $1.95 \mathrm{~kg}$ were used. The DSP was estimated using the homogenizing technique. Measurements of the external genitalia and the post slaughter traits were subjected to regression analysis using the DSP as the dependent variable to come up with prediction equations for estimating the DSP from the studied traits. The coefficients of determination $\left(\mathbf{R}^{2}\right)$ for fitted functions were determined.

Paired testicular weight (PTW) had a high and positive correlation $(r=0.64$, $P>0.01<0.05)$ with the DSP, paired epididymis weight caudal $\left(P E W_{3}\right)$ also had a positive and significant correlation $(r=0.78, P<0.01)$ with the $D S P$. Both the paired scrotal length (PSL) and paired scrotal diameter (PSD) had a positive but insignificant correlation $(r=0.40, P>0.05)$ each with the $D S P$. The $R^{2}$ varied from 0.00 to 1.15

Either PSD or PSL could be used to predict DSP in a live buck since it has positive correlation with DSP as the post slaughter traits such as PTW and PEW . $_{3}$ 


\section{INTRODUCTION}

Rabbit has been classified as the species of choice with different attributes and the potential of becoming the Third World's major animal protein supplier. The practical potential of rabbit meat in meeting the world's protein needs has been equally established (Chen et al., 1978). Rabbits have a very high growth rate comparable only to that of broiler chickens (Rao et al., 1977). Its meat is relatively cheaper and comparatively lower in cholesterol than meats from other animals such as pork, beef, mutton and chevon which are also more expensive.

There have been several advances to better exploit the reproductive potential of animals for improved animal production. Such advances have culminated in great development and application to swine, sheep, poultry, cattle and goat. However, rabbit production seems to be comparatively lacking in the application and exploitation of some of these advances.

The reproductive function of the male involves the production of spermatozoa and the deposition of these into the female reproductive tract. Sperm cells are produced in the seminiferous tubules of the testes and are then transported through the rete testes to the epidimymides, where they are stored and matured.

The production of sperm cells is a continuous process once it has been initiated. However, it can change in rate at times in some species. Sperm cells production rates established for various animals are breed dependent (Dott and Skimmer, 1967; Igboeli and Rakha, 1971; Lino, 1972).

Fertility can be measured for the male by the percentage of service resulting in conception (Devendra and Burns, 1979). The evaluation of breeding soundness remains an important aspect of the farmer's reproductive management practice. Several measurement criteria, such as scrotal circumference, sperm motility and morphology, have been extensively studied in some bulls (Memon, 1983). Few of these reports are available for most breeds of cattle, sheep and goats indigenous to sahelian zone of the north-eastern Nigeria. Osinowo et al. (1987) suggested that scrotal circumference was highly correlated to paired testes weight, volume and goanadal epididymis reserves in bulls $(r=0.99)$ and this is related to sperm production potential. Also, Bongso et al. (1982) affirmed that scrotal circumference is an indirect means of measuring testicular weight and sperm production. Marire (1986) reported in goat a high correlation between scrotal circumference with gonadal sperm reserve and epididymal sperm reserve as well as epididymis weight and gonadal sperm reserve. Generally, daily sperm production has been variously reported in other animal species to be positively correlated with scrotal circumference (Farotimi, 2005). Highly significant correlations were found between daily sperm production and scrotal length, width, and circumference in Maradi bucks (Carew and Egbunike, 1980).
Specifically, the objective of this study is to evaluate the correlation between some external genitalia morphometric indices, testicular parameters and daily sperm production of the rabbit with a view of assisting rabbit farmers make informed early selection from pre-pubertal male rabbits thereby enhancing the selective process for reproduction purposes.

\subsection{MATERIALS AND METHODS}

\subsection{Experimental site}

The study was conducted at the rabbitry of the teaching and research farm of the University of Ibadan, Ibadan, Nigeria $\left(7^{\circ} 27^{\prime} \mathrm{N}\right.$ and $3^{\circ} 45^{\prime} \mathrm{E}$, at altitude $200-300$ $\mathrm{m}$ above sea level with an average annual rainfall of $1250 \mathrm{~mm}$ ).

\subsection{Animals Management}

Twenty male pubertal dutch rabbits were sourced from two a commercial unit for this study. Their body masses or weights range between 1.66 to $1.95 \mathrm{~kg}$.

The animals were housed in individual metal cages and covered roundabout with wire mesh for cross ventilation. The rabbits were fed on forage (Aspillia africana) generously as at when due for a period of two weeks that the animals spent on the farm for stabilization. They were not denied access to $a d$ libitum supply of clean, cool and sufficient water. They were vaccinated against the incidence of coccidiosis.

\subsection{Data Collection}

\subsubsection{Measurement before sacrifice}

The scrotal length and diameter were taken using a venier calliper.

\subsubsection{Measurement after Sacrifice}

The rabbits were stunned before cervical dislocation; the abdominal cavity was cut open through the ventral side to expose the organs. The organs were removed and freed of connective tissues and fat. The weight, volume, and density of the testes were taken and recorded.

Testes Weight: The left and right testes were weighed separately using a very sensitive scale (Metler balance). The results were recorded to the nearest $0.001 \mathrm{~g}$.

Testes Volume: The volumes of the left and right testes were taken separately using the Archimedes's Principle of water displacement with the use of a $25 \mathrm{ml}$ measuring cylinder. The results were recorded in $\mathrm{ml}$;

Testis Density: This was determined from calculation using the formula:

Left tests density $(L T D)=\quad$ LTW 


$$
\text { Right testis density }(R T D)=\frac{\text { LTV }}{\text { RTW }}
$$$$
\text { Paired testis density }(P T D)=\frac{\mathrm{LTW}+\mathrm{RTW}}{\mathrm{LTV}+\mathrm{RTV}}
$$

NB: LTW: left testis weight, RTW: right testis Weight, LTV: left testis volume and RTV: right testis volume

Epididymal Weight: The left and right epididymes were separated into the caput; corpus and caudal .The weights were taken using the Metler Toledo sensitive scale

\subsection{Daily Sperm Production (DSP) Determination by Homogenizing Technique:}

After slaughter, the genital tract was harvested; the testes and epididymes were removed from the tunics and were freed of fat and unwanted connective tissues. The tract was then separated into right and left testes, right and left caput, corpus and caudal epididymes and weighed. The testes, caput, corpus and caudal epididymes were homogenized separately for 1 minute in $4 \mathrm{ml}$ of normal saline solution $(0.9 \%$ $\mathrm{NaCl})$.
The suspensions were mixed and transferred into test tubes. All samples were covered and stored for 24 hours at $4^{\circ} \mathrm{C}$. Counting done haemocytometrically using an improved Neubauer haematocytometer and the daily sperm production was calculated using the formula proposed by Amann (1970).

\section{$D S P=\underline{\text { Testis Sperm Count }}$ Time Divisor}

Time Divisor $=$ Length of one cycle of the seminiferous epithelium $x$ Percentage of cycle represented by spermatids counted.

A time divisor of 3.43 proposed by Amann (1970) was used.

\subsection{Statistical Analysis}

The data collected were subjected to descriptive statistics using Procedure Mean (PROC MEAN) of SAS (1999). Further analyses were done using Procedure Correlation (PROC CORR) and Procedure Regression (PROC REG) of SAS (1999). The descriptive statistics show uniformity among the studied animals as there are no significant variations in both the studied post slaughter traits (Table 1) and external genitalia (Table 2) of the bucks.

Table 1: The descriptive statistics of the post slaughter traits

\begin{tabular}{|c|c|c|c|}
\hline Traits & Mean \pm SE & SD & CV \\
\hline LTW & $2.80 \pm 0.20$ & 0.62 & 22.21 \\
\hline RTW & $2.65 \pm 0.20$ & 0.63 & 23.70 \\
\hline PTW & $5.44 \pm 0.39$ & 1.23 & 22.59 \\
\hline LEW $_{1}$ & $0.21 \pm 0.02$ & 0.05 & 25.14 \\
\hline LEW $_{2}$ & $0.06 \pm 0.01$ & 0.02 & 35.48 \\
\hline LEW $_{3}$ & $0.37 \pm 0.03$ & 0.10 & 26.91 \\
\hline REW $_{1}$ & $0.22 \pm 0.02$ & 0.06 & 28.14 \\
\hline REW $_{2}$ & $0.06 \pm 0.01$ & 0.03 & 62.54 \\
\hline REW $_{3}$ & $0.39 \pm 0.02$ & 0.06 & 15.82 \\
\hline $\mathrm{PEW}_{1}$ & $0.42 \pm 0.04$ & 0.12 & 27.98 \\
\hline $\mathrm{PEW}_{2}$ & $0.12 \pm 0.04$ & 0.05 & 40.68 \\
\hline $\mathrm{PEW}_{3}$ & $0.76 \pm 0.05$ & 0.16 & 20.74 \\
\hline LTV & $0.51 \pm 0.06$ & 0.20 & 38.61 \\
\hline RTV & $0.43 \pm 0.05$ & 0.16 & 38.06 \\
\hline PTV & $0.94 \pm 0.11$ & 0.11 & 37.93 \\
\hline
\end{tabular}

LTW = left testis weight, RTW = right testis weight, PTW = paired testis weight $\mathrm{LEW}_{1}$ = left epididymal weight (caput), $\mathrm{LEW}_{2}$ left epididymal weight (corpus), $\mathrm{LEW}_{3}=$ left epididymal weight (caudal), $\mathrm{REW}_{1}$ = right epididymal weight (caput), $\mathrm{REW}_{2}$ right epididymal weight (corpus), $\mathrm{REW}_{3}=$ right epididymal weight (caudal), $\mathrm{LTV}=$ left testis volume, $\mathrm{RTV}=$ right testis volume, $\mathrm{PTV}=$ paired testis volume $\mathrm{SD}=$ standard deviation, $\mathrm{SE}=$ standard error, $\mathrm{CV}=$ coefficient of variation . 
Table 2: Descriptive statistics of the external genitalia of the bucks

\begin{tabular}{|llll|}
\hline Traits & Mean \pm SE & SD & CV \\
\hline LSL & $6.55 \pm 0.03$ & 0.10 & $\mathbf{1 . 4 8}$ \\
RSL & $5.72 \pm 0.02$ & 0.08 & $\mathbf{1 . 3 8}$ \\
LSD & $1.04 \pm 0.03$ & 0.08 & $\mathbf{8 . 1 1}$ \\
RSD & $0.96 \pm 0.20$ & 0.05 & $\mathbf{5 . 3 8}$ \\
PSL & $12.27 \pm 0.05$ & 0.16 & $\mathbf{1 . 2 8}$ \\
PSD & $2.00 \pm 0.04$ & 0.12 & $\mathbf{5 . 7 7}$ \\
\hline
\end{tabular}

$\mathrm{LSL}=$ left scrotal length, $\mathrm{RSL}=$ right scrotal length, $\mathrm{LSD}=$ left scrotal diameter, $\mathrm{RSD}=$ right scrotal diameter, $\mathrm{PSL}=$ paired scrotal diameter, $\mathrm{PSD}=$ paired scrotal diameter .

\section{RESULTS AND DISCUSSION}

Table 3: the correlation coefficient between the post slaughter traits and the daily sperm production (DSP

\begin{tabular}{lccccc}
\hline Traits & LTW & RTW & LTV & RTV & DSP \\
\hline LTW & 1.00 & $0.94^{\star *}$ & $0.71^{*}$ & $0.70^{*}$ & 0.62 \\
RTW & & 1.00 & $0.73^{*}$ & $0.73^{*}$ & $0.64^{*}$ \\
LTV & & & 1.00 & $0.96^{\star *}$ & 0.20 \\
RTV & & & & 1.00 & 0.15 \\
DSP & & & & & 1.00 \\
\hline
\end{tabular}

LTW = left testis weight, RTW = right testis weight, LTV = left testis volume, RTV = right testis volume. Significance level at $1 \%\left(^{* *}\right)(P \leq 0.01)$

Significance level at $5 \%\left(^{*}\right)(P>0.01 \leq 0.05)$

Values not superscripted are non significant. $(P>0.05)$

The above relationship (Table 3 ) shows that RTW is highly positively correlated with the DSP $(r=0.64, P>$ $0.01<0.05)$. It shows that both RTW and LTW can be used to predict daily sperm production in the rabbit bucks though RTW seems to be a better indicator of predicting DSP than LTW as it shows a higher positive and significant correlation with DSP than the LTW. Both LTV and RTV do not show a significant correlation with DSP $(r=0.02, P>0.05)$ and $(r=0.15$, $P>0.05)$ respectively.

Table 4: the correlation relationship between daily sperm production (DSP) and the paired

\begin{tabular}{llllllll}
\multicolumn{7}{c}{ post slaughter traits. } \\
\hline Traits & PTW & PTV & PTD & PEW & PEW & PEW & DSP \\
\hline PTW & 1.00 & $0.74^{*}$ & -0.16 & -0.22 & 0.46 & $0.80^{\star *}$ & $0.64^{\star}$ \\
PTV & & 1.00 & $-0.75^{\star \star}$ & 0.07 & 0.50 & 0.48 & 0.18 \\
PTD & & & 1.00 & -0.45 & -0.24 & 0.18 & 0.39 \\
PEW $_{1}$ & & & & 1.00 & -0.11 & -0.55 & $-0.65^{\star}$ \\
PEW $_{2}$ & & & & & 1.00 & 0.39 & 0.29 \\
PEW & & & & & & 1.00 & $0.78^{\star *}$ \\
DSP & & & & & & & 1.00 \\
\hline
\end{tabular}

PTW $=$ paired testis weight, $\mathrm{PTV}=$ paired testis volume, $\mathrm{PTD}=$ paired testis density, $\mathrm{PEW} \mathrm{W}_{1}$ paired epididymal weight caput, $\mathrm{PEW}=$ paired epididymal weight corpus, $\mathrm{PEW} \mathrm{EW}_{3}=$ paired epididymal weight caudal, DSP = daily sperm production .

Significance level at $1 \%\left({ }^{* *}\right)(P \leq 0.01)$

Significance level at $5 \%\left(^{*}\right)(P>0.01 \leq 0.05)$

Values not superscripted are non significant. $(P>0.05)$

The above (Table 4) illustrates a high positive correlation $(r=0.64, P>0.01<0.05)$ between paired testis weight (PTW) and daily sperm production (DSP) while paired epididymal weight caput $\left(\mathrm{PEW}_{3}\right)$ has a negative and significant correlation with DSP $(r=$ $0.65, \mathrm{P}>0.01<0.05)$. Paired epididymal weight caudal 
$\left(\mathrm{PEW}_{3}\right)$ equally correlates positively $(r=0.78, \mathrm{P}<0.01)$ with the DSP. This suggests that the caudal epididymis stores a greater number of mature spermatozoa than the caput and corpus epididymes, hence, a better predictor of the DSP than the caput and corpus epididymes.
PEW caudal also has a high positive correlation with the PTW $(r=0.80, P<0.01)$, meaning that each of them could be used as a predictor of the daily sperm production in the rabbit bucks. Among all testicular traits above, PTW is a better indicator of the DSP than the PTV and PTD.

Table 5: correlation relationship between the daily sperm production (DSP) and the external genitalia

\begin{tabular}{llllllll}
\hline Traits & LSL & RSL & LSD & RSD & PSL & PSD & DSP \\
& & & & & & & \\
\hline LSL & 1.00 & 0.58 & $0.81^{* *}$ & 0.44 & $0.91^{* *}$ & 0.79 & 0.38 \\
RSL & & 1.00 & $0.87^{* *}$ & 0.22 & $0.86^{\star *}$ & $0.73^{\star}$ & 0.33 \\
LSD & & & 1.00 & 0.41 & $0.94^{* *}$ & $0.91^{* *}$ & 0.29 \\
RSD & & & & 1.00 & 0.38 & $0.75^{\star *}$ & 0.41 \\
PSL & & & & & 1.00 & $0.86^{* *}$ & 0.40 \\
PSD & & & & & & 1.00 & 0.40 \\
DSP & & & & & & & 1.00 \\
\hline
\end{tabular}

$\mathrm{LSL}=$ left scrotal length, $\mathrm{RSL}=$ right scrotal length, $\mathrm{LSD}=$ left scrotal diameter, $\mathrm{RSD}=$ right scrotal diameter, PSL = paired scrotal diameter, $\mathrm{PSD}=$ paired scrotal diameter, $\mathrm{DSP}=$ daily sperm production.

Significance level at $1 \%\left({ }^{* \star}\right)(\mathrm{P} \leq 0.01)$

Significance level at $5 \%\left(^{*}\right)(P>0.01 \leq 0.05)$

Values not superscripted are non significant. $(P>0.05)$

All the above (table 5) external genitalia traits show a positive, non significant correlation with the daily sperm production (DSP) $(\mathrm{P}>0.05)$, with the right testis diameter (RSD) having the highest correlation $(r=$ $0.41, \operatorname{Pr}>0.05)$, followed by the paired testis length (PSL) and the paired testis diameter (PSD) $(r=0.40, P$
$>0.05$ ) each. This means any of the RSD, PSL or PSD could be a useful and reliable indicator in predicting the daily sperm production in rabbit bucks than the left scrotal length (LSL) $(r=0.38, P>0.05)$, right scrotal length (RSD) $(r=0.33, P>0.05)$ and the left scrotal diameter (LSD) $(r=0.29, P>0.05)$.

Table 6: the regression equation predicting the daily sperm production (DSP) from the external genitalia: $Y=a+b X$.

\begin{tabular}{lllll}
\hline Traits & Function & SE & $\mathbf{R}^{2}$ & Significance \\
\hline LSL & $\mathrm{Y}=-39.15+7.91 \mathrm{X}$ & 6.74 & 0.15 & $\mathrm{NS}$ \\
RSL & $\mathrm{Y}=-35.58+8.43 \mathrm{X}$ & 8.49 & 0.11 & $\mathrm{NS}$ \\
LSD & $\mathrm{Y}=5.38+7.00 \mathrm{X}$ & 8.04 & 0.09 & $\mathrm{NS}$ \\
RSD & $\mathrm{Y}=-2.65+15.92 X$ & 12.53 & 0.17 & $\mathrm{NS}$ \\
PSL & $\mathrm{Y}=-50.89+5.18 \mathrm{X}$ & 4.14 & 0.16 & $\mathrm{NS}$ \\
PSD & $\mathrm{Y}=-1.17+6.90 \mathrm{X}$ & 5.64 & 0.16 & $\mathrm{NS}$ \\
\hline
\end{tabular}

$\mathrm{LSL}=$ left scrotal length, $\mathrm{RSL}=$ right scrotal length, $\mathrm{LSD}=$ left scrotal diameter, $\mathrm{RSD}=$ right scrotal diameter, $\mathrm{PSL}=$ paired scrotal diameter, $\mathrm{PSD}=$ paired scrotal diameter, $\mathrm{DSP}=$ daily sperm production, $\mathrm{Y}=\mathrm{DSP}=$ dependent variable, $\mathrm{X}=$ independent variables ( $L S L, R S L, R S D$ etc), $\mathrm{SE}=$ standard error of the regression, $\mathrm{R}^{2}=$ coefficient of determination

The above prediction equations (Table 6) show a nonsignificant association with the daily sperm production (DSP) $(P>0.05)$ with the $R^{2}$ ranging from 0.09 to 0.17 . The right scrotal diameter (RSD) has the highest coefficient of determination (0.17) which makes it the most suitable predictor of daily sperm production among all the post slaughter traits. Paired scrotal diameter (PSD) and the paired scrotal length (PSL) ranked after the RSD by having a coefficient of determination $\left(R^{2}\right)$ of 0.16 each. Hence, " $Y=-2.65+$ $15.92 X "$ seems to be the best prediction equation of the above equations. 
Table 7: The regression equation predicting the daily sperm production (DSP) from the post slaughter traits

\begin{tabular}{lllll}
\hline Traits & Function & SE & R2 & Significance \\
\hline LTW & $Y=7.02+1.99 X$ & 0.90 & 0.38 & NS \\
RTW & $Y=7.19+2.06 X$ & 0.87 & 0.41 & NS \\
LTV & $Y=11.60+2.02 X$ & 3.53 & 0.04 & NS \\
RTV & $Y=11.85+1.82 X$ & 4.29 & 0.02 & $*$ \\
PTW & $Y=6.95+1.04 X$ & 0.44 & 0.41 & \\
PTV & $Y=11.69+1.00 X$ & 1.96 & 0.03 & NS \\
PTD & $Y=10.31+0.37 X$ & 0.31 & 0.15 & NS \\
\hline
\end{tabular}

LTW = left testis weight, RTW = right testis weight, LTV = left testis volume, RTV = right testis volume, PTW = paired testis weight, PTV = paired testis volume, PTD = paired testis density. $\mathrm{Y}=\mathrm{DSP}=$ dependent variable, $\mathrm{X}=$ independent variables, $\mathrm{SE}=$ standard error of the regression, $\mathrm{R}^{2}=$ coefficient of determination

The right testis weight (RTW) and the paired testis weight (PTW) in the table above (Table 7) are strongly and positively associated with the daily sperm production $(P>0.01<0.05)$ with the coefficient of determination $\left(R^{2}\right)$ of 0.41 each, followed by the left testis weight $(P>0.05)$ with the coefficient of determination $\left(R^{2}\right)$ of 0.38 , though not significant. The other external genitalia are weakly associated with the daily sperm production (DSP). Either of the prediction equations with the coefficient of determination $\left(R^{2}\right)$ of 0.41 above could be a good predictor of daily sperm production in the rabbit bucks. The coefficient of determination ranges from 0.02 to 0.41 .

Table 8: the regression equation predicting the daily sperm production (DSP) from the epididymal traits

\begin{tabular}{lllll}
\hline Traits & Function & SE & R2 & Significance \\
& & & & \\
\hline LEW $_{1}$ & $Y=19.05-30.31 X$ & 7.90 & 0.65 & ${ }^{* *}$ \\
LEW $_{2}$ & $Y=12.60+0.43 X$ & 31.24 & 0.00 & NS \\
LEW $_{3}$ & $Y=6.60+16.22 X$ & 4.17 & 0.65 & $* *$ \\
REW $_{1}$ & $Y=16.08-15.98 X$ & 10.21 & 0.23 & NS \\
REW $_{2}$ & $Y=11.32+23.75 X$ & 18.84 & 0.17 & NS \\
REW $_{3}$ & $Y=3.31+23.96 X$ & 7.82 & 0.54 & $*$ \\
PEW $_{1}$ & $Y=17.29-11.13 X$ & 4.60 & 0.42 & $* *$ \\
PEW $_{2}$ & $Y=11.19+12.09 X$ & 14.02 & 0.09 & NS \\
PEW $_{3}$ & $Y=4.89+10.17 X$ & 2.7 & 0.64 & $* *$ \\
\hline
\end{tabular}

$\mathrm{LEW}_{1}=$ left epididymal weight caput, $\mathrm{REW}_{1}=$ right epididymal weight caput

$R E W_{2}=$ right epididymal weight corpus, $\mathrm{LEW}_{2}=$ left epididymal weight corpus

$\mathrm{LEW}_{3}=$ left epididymal weight caudal, REW3 = right epididymal weight caudal

$\mathrm{PEW}_{1}$ = paired epididymal weight caput, $\mathrm{PEW} \mathrm{W}_{2}$ = paired epididymal weight corpus,

$\mathrm{PEW}_{3}=$ paired epididymal weight caudal.

$\mathrm{Y}=\mathrm{DSP}=$ dependent variable, $\mathrm{X}=$ independent variables,

$\mathrm{SE}=$ standard error of the regression, $\mathrm{R}^{2}=$ coefficient of determination

${ }^{* *}=$ level of significance at $1 \%(P \leq 0.01)$

* = level of significance at $5 \%(P>0.01 \leq 0.05)$

$\mathrm{NS}=$ not significant at $(\mathrm{P}>0.05)$

The above epididymal traits (Table 8 ) have a better association with the daily sperm production than the previous traits examined. The coefficients of determination range from 0.00 to 0.65 with the left epididymal weight (caput) (LEW 1 ) and left epididymal weight (caudal) ( $\mathrm{LEW}_{3}$ ) having the highest $\mathrm{R}^{2}$ of 0.65 and high significant and positive association with the daily sperm production $(P<0.01)$, this is followed by the paired epididymal weight caudal $\left(\mathrm{PEW}_{3}\right)$ having a coefficient of determination $\left(R^{2}\right)$ of 0.64 and it is equally strongly associated with the daily sperm production $(P<0.01)$, paired epididymal weight caput is also strongly associated significantly $(P<0.01)$ with the daily sperm production but not as strong as the first three discussed earlier as it has a coefficient of determination $\left(R^{2}\right)$ of 0.42 . Right epididymal weight caudal $\left(\mathrm{REW}_{3}\right)$ appeared to have the less significant association $(P<0.05)$ with the daily sperm production (DSP) but its coefficient of determination $\left(R^{2}\right), 0.54$, is higher than that observed the paired testis weight caput. It means the prediction equations of $\mathrm{LEW}_{1}$, $\mathrm{LEW}_{3}$, are the predictor of the daily sperm production followed by that of the $\mathrm{PEW}_{3}$.

Generally, the high significant and positive correlation recorded in this experiment between paired testis weight (PTW), right testis weight (RTW) and the 
daily sperm production (DSP) $(r=0.64, \operatorname{Pr}<0.01)$ was in agreement with Osinowo et al. (1987) that recorded high correlation $(r=0.99)$ between scrotal circumference and testis weight and concluded that this is related to the daily sperm production in the bulls. This means that either paired testis weight (PTW) or the right testis could be used conveniently in predicting the daily sperm production (DSP) in the rabbit bucks.

There is a consonance between Nkanga and Egbunike (1980), Bongso et al. (1982) and this experiment in terms of the relationship between the daily sperm production and the paired testis weight (PTW) as they recorded high correlation $(r=0.98, P$ $<0.01$ ) between the PTW and the DSP.

In agreement with the report of Dauda and Shoyinka (1983) that recorded a high positive correlation between the scrotal circumference $(r=0.88)$ and the caudal epididymal spermatozoa (paired), a high positive correlation was equally recorded $(r=0.80$, $P=<0.01$ ) in this experiment between the paired testis weight and the paired caudal epididymal weight.

Paired scrotal length (PSL) and paired scrotal diameter (PSD) give a high positive correlation $(r=$ $0.40, P>0.05$ ) with the daily sperm production in this experiment and this is in support of the report of Carew and Egbunike (1980) that recorded high significant correlations between the daily sperm production (DSP) and scrotal length, width and circumference in Maradi bucks. Since the scrotal circumference is highly positively correlated with the paired scrotal length (PSL), paired scrotal diameter (PSD) and the daily sperm production (DSP), then either of PSL or PSD could be used as indicator for predicting the reproductive potentials of rabbit bucks.

The correlation analysis further shows a very high positive correlation between the paired testis weight and the DSP. Also, paired epididymal weight (caudal) correlates very highly and positively at a very significant level with the DSP.

Among the external genitalia, paired scrotal length and diameter as well as the right scrotal diameter have the highest positive correlation with the DSP.

Regression analysis was done to arrive at prediction equations, using the studied traits as the dependent variables, for estimating the daily sperm production. In general, paired scrotal diameter (PSD), paired scrotal length (PSL), right scrotal length (RSL), paired testis weight (PTW) and paired epididymal weight caudal $\left(\mathrm{PEW}_{3}\right)$ are good indicators for determining the daily sperm production in domestic rabbit bucks.

\section{CONCLUSION}

From this study, it is clear that the paired testis weight and paired epididymis weight caudal are highly correlated with the daily sperm production. There are strong correlations also among these post slaughter traits and the external testicular traits such as paired scrotal length, paired scrotal diameter and scrotal circumference. It can therefore be concluded that any of the external testicular traits as established in this study may be used as a tool to predict the daily sperm production and reproduction potential in rabbit bucks while selection process for breeding soundness is being considered in reproduction procedure.

\section{REFERENCES}

Abdullah, A.R.; Sokunbi, O.A.; Omisola, O.O. and Adewumi, M.K. (2003). Interrelationship btw body weight and body linear measurements in domestic rabbit. Proc. NSAP conf. vol.28. Pp.133-136.

Amann, R.P. (1970). Sperm production rates. In: the testis. Ed. A.D. Johnson, W.R. Gomes and N.L. Van Denmark. Academic press, N.Y.

Bongso, T.A., Jainudeen, M.R. and Sithzalrah, A. (1982). Relationship of scrotal circumference to age, body weight and onset of spermatogenesis in goats. Theriogenesis. 18(15):513-524

Carew, B. and Egbunike, G.N. (1980). Sperm production rate in Maradi goats extensively Managed in a tropical environmental. In : $9^{\text {th }}$ int'l. Congress of Anim. Reprod. \& artificial insemination. $16^{\text {th }}-20^{\text {th }}$ June, 1980. Madrid, Spain.

Cheeke, P.R. (1986). Potentials of rabbit prod. in the tropical\&sub-tropical Agric. Sys. J.

Chen, C.P.; Rao, D.R.; Sunki, G.R. and Johnson, W.M. (1978). Effects of weaning and slaughter ages upon rabbit meat prod. I. body weight, feed efficiency

mortality. J. Anim. Sci. 46(3): 573-577

Chineke,C.A.(2000). Characterization of physical body traits of domestic rabbit in the humid tropics, proc. $25^{\text {th }}$ Annual conf., NSAP, 19-23 March,2000, Umudike, pp 237.

Dauda, C. S. and Shoyinka, V. (1983). Scrotal circumference, daily sperm production and epididymal spermatozoa of the indigenous Bunaji \& Sokoto Gudali bulls in Nigeria. Br. Vet J. 139: 487-489.

Devendra, C. and Burns, M. (1979). Goats prod. in the tropics. Farnham Royal, England.Common Wealth Agricultural Bureau.

Dott, H.M. and Skimmer, J. (1967). Assessment of extragonadal sperm reserves in suftolk rams. $J$. Agric. Sci. (camb) 69; 293-295.

Farotimi O.J. (2005). Relationships between body weight, body linear measurements and reproductive potential of dutch rabbit bucks. B. Agric Dissertation, Department of Animal science, university of Ibadan, Nigeria.

Igboeli, G. and Rakha, A. M. (1971). Gonadal and extra gonadal sperm reserves of indigenous Central African bulls. J. Reprod. Fert. 25: 107-109.

Lino, B.F. (1972). The output of spermatozoa in rams. II. Relationship to SC, TW and the 359-366.

Marire, B.N. (1987). Prediction of sperm production from scrotal circumference in red sokoto bucks. Proceedings $11^{\text {th }}$ Annual conf. NSAP, ABU, Zaria.148-151

Memon, A.M. (1983). Large animals practice vol.5 $(3,619)$. Vet. Clinic of North America. 
Nkanga, E.E. and Egbunike, G.N. (1990). Daily sperm production of the domestic fowl (Gallus gallus) determined by the quantitative testicular histology and homogenate methods. J. Trop. Anim. Prod. $1: 1-18$

Osinowo, O.A.; Molokun, E.C.I. and Osun, D.I. (1987). Growth and testicular Development in Bunaji bulls. J. Anim. Prod. Res. 1(1): 1-12.
Rao, D.R.; Sunki, G.R. and Johnson, W.M. (1978). Post natal growth of New Zealand white rabbit. J. anim. Sci. 44: 1021 - 1025.

SAS (1999). Statistical Analysis System. User's guide: statistics. SAS institute Inc. Cary NC 275513 USA.

Cite this Article: Olarotimi OJ, Sokunbi OA, Abdullah A (2015). Determination of Daily Sperm Production (DSP) in Rabbit (Oryctolagus cuniculus) Bucks using Testicular Parameters. Greener Journal of Agricultural Sciences, 5(4): 141-148, http://doi.org/10.15580/GJAS.2015.4.070715086. 